\title{
Platelet-activating protamine-heparin-antibodies lead to higher protamine demand in patients undergoing cardiac surgery
}

\author{
Philippe Grieshaber, MD, ${ }^{\mathrm{a}}$ Tamam Bakchoul, MD, PhD, ${ }^{\mathrm{b}}$ Jochen Wilhelm, $\mathrm{PhD},{ }^{\mathrm{c}}$ Alexander Wagner, MD, \\ Matthias Wollbrück, MD, ${ }^{\mathrm{d}}$ Andreas Böning, $\mathrm{MD}, \mathrm{PhD},{ }^{\mathrm{a}}$ and Ulrich Sachs, $\mathrm{MD}, \mathrm{PhD}^{\mathrm{e}}$
}

\begin{abstract}
Objectives: Platelet-activating antibodies against protamine-heparin-complexes were described in patients undergoing cardiac surgery, but their clinical consequences remain unclear. This prospective single-center observational study aimed to describe the prevalence and clinical consequences of protamine-heparincomplex antibodies in patients undergoing cardiac surgery with cardiopulmonary bypass.
\end{abstract}

Methods: A total of 200 patients undergoing cardiac surgery with cardiopulmonary bypass were included. Blood samples were collected preoperatively and 1 hour, 24 hours, and 7 days after weaning from cardiopulmonary bypass. All sera were tested for the presence of protamine-heparin-complex antibodies using a modified heparin-induced platelet-activation assay. Specific Fc $\gamma$ receptor IIadependent platelet activation was confirmed by repeated testing in the presence of the $\mathrm{Fc} \gamma$ receptor IIa-blocking antibody IV.3.

Results: Samples from 185 patients were obtained, of whom 24 patients $(13 \%)$ were positive for protamine-heparin-complex antibodies preoperatively. In all positive samples, functional reactivity was reversible in the presence of IV.3. Although patients with a preoperative presence of protamine-heparin-complex antibodies were significantly older compared with patients negative for protamine-heparin-complex antibodies $(73 \pm 9.8$ years vs $68 \pm 10$ years, $P=.037$ ), no other potential risk factors were identified at 1 day before operation. Patients with protamine-heparin-complex antibodies required significantly more protamine to neutralize heparin $(47.66 \mathrm{mg}$ vs $41.67 \mathrm{mg}, P=.027)$. Protamineheparin-complex antibodies have no significant influence on perioperative platelet numbers, bleeding complications, transfusion requirement, thromboembolic events, major cardiovascular and cerebrovascular events, inflammation parameters, or kidney function.

Conclusions: Protamine-heparin-complex antibodies occur frequently in patients undergoing cardiac surgery on cardiopulmonary bypass, resulting in specific platelet activation in vitro. Protamine-heparin-complex antibodies are associated with increased protamine requirement after cardiopulmonary bypass and possibly slower recovery of platelet numbers. (J Thorac Cardiovasc Surg 2015;150:967-73)

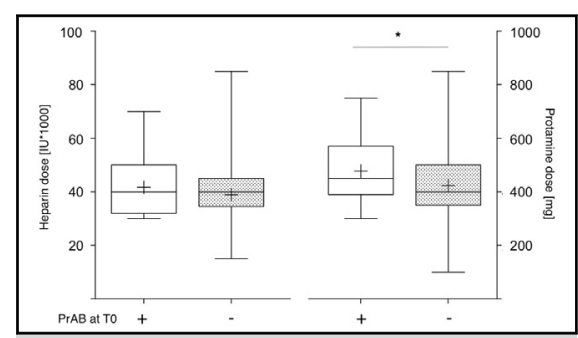

Although heparin doses are similar, PrAB-positive patients require higher doses of protamine.

Central Message

PrAB in patients undergoing cardiac surgery have effects resulting in higher protamine demand to neutralize heparin-mediated anticoagulation.

\section{Perspective}

Platelet-activating PrAB affect the perioperative protamine management and might influence the perioperative outcome of patients undergoing cardiac surgery. Further characterization of the effects in larger patient cohorts will lead to a better understanding of the clinical relevance of these antibodies. This could imply preoperative testing for the presence of these antibodies in the future.

See Editorial Commentary page 974.
From the ${ }^{\mathrm{a}}$ Department of Adult and Pediatric Cardiovascular Surgery, University
Hospital Giessen, Giessen, Germany; ${ }^{\mathrm{b}}$ Department of Transfusion Medicine,
Ernst-Moritz-Arndt University Greifswald, Greifswald, Germany; ${ }^{\mathrm{c}}$ Department
of Internal Medicine, German Center for Lung Research, Justus Liebig University,
Giessen, Germany; ${ }^{\mathrm{d}}$ Department of Anaesthesiology and Intensive Care Medicine
University Hospital Giessen, Giessen, Germany; and ${ }^{\mathrm{e}}$ Institute for Clinical Immu-
nology und Transfusion Medicine, Justus Liebig University Giessen, Giessen, Ger-
many.
This trial was funded by the University Hospital Giessen and Marburg Research Fund.
The authors have received research support from The German Heart Foundation, the University Hospital Giessen, and Marburg Research Fund (PG and AB) and the German Research Foundation (US).

Received for publication Oct 21, 2014; revisions received May 14, 2015; accepted for publication July 16, 2015; available ahead of print Aug 19, 2015.

Address for reprints: Philippe Grieshaber, MD, Department of Adult and Pediatric Cardiovascular Surgery, University Hospital Giessen, Rudolf-Buchheim-Str 7, DE-35392 Giessen, Germany (E-mail: Philippe.grieshaber@chiru.med. uni-giessen.de).

$0022-5223 / \$ 36.00$

Copyright (C) 2015 by The American Association for Thoracic Surgery

http://dx.doi.org/10.1016/j.jtcvs.2015.07.057 


$$
\begin{aligned}
& \text { Abbreviations and Acronyms } \\
& \mathrm{ACT}=\text { activated clotting time } \\
& \mathrm{CI}=\text { confidence interval } \\
& \mathrm{CPB}=\text { cardiopulmonary bypass } \\
& \mathrm{Fc} \gamma \mathrm{RIIa}=\mathrm{Fc} \gamma \text { receptor IIa } \\
& \text { HIT = heparin-induced thrombocytopenia } \\
& \text { MACCE }=\text { major cardiovascular and } \\
& \text { cerebrovascular events } \\
& \mathrm{NPH}=\text { neutral protamine Hagedorn } \\
& \mathrm{OR}=\text { odds ratio } \\
& \mathrm{Pr} \mathrm{AB}=\text { protamine-heparin-complex antibody } \\
& \text { T0 }=1 \text { day before operation } \\
& \mathrm{T} 1=1 \text { hour after weaning from } \\
& \text { cardiopulmonary bypass } \\
& \mathrm{T} 2=24 \text { hours after operation } \\
& \text { T3 }=7 \text { days after operation }
\end{aligned}
$$

Protamine, an arginine-rich, positively charged protein physiologically involved in sperm head stabilization during spermatogenesis, ${ }^{1}$ is widely used in medicine as a stabilizing adjunct to insulin and a neutralizer of heparin-mediated anticoagulation, particularly after cardiac surgical procedures using cardiopulmonary bypass (CPB). ${ }^{2,3}$ In addition to various side effects including systemic hypotension, anaphylactic reaction, and pulmonary vasoconstriction with secondary right heart failure, ${ }^{4-6}$ thrombocytopenia after protamine administration following $\mathrm{CPB}$ has been described. ${ }^{7,8}$ Furthermore, protamine and protamine-heparin-complexes are immunogenic. ${ }^{9-11}$ Lee and colleagues ${ }^{12}$ retrospectively screened patients undergoing CPB for the presence of protamine-heparin-complex antibodies $(\operatorname{PrAB})$. The prevalence of $\mathrm{Pr} \mathrm{AB}$ in patients undergoing cardiac surgery ranged from $1 \%$ to $9.6 \%$ preoperatively increasing to $26.6 \%$ to $31 \%$ 10 and 30 days postoperatively, respectively. ${ }^{10,12}$ Different risk factors for the preoperative presence of PrAB have been suggested, including obesity, arterial hypertension, previous myocardial infarction, previous cardiac surgery with $\mathrm{CPB}$, nicotine abuse, and diabetes mellitus; however, no significant independent predictor has been characterized so far. ${ }^{10,12,13}$ A subgroup of PrAB shows similar characteristics as antiplatelet factor $4 /$ heparin antibodies in heparin-induced thrombocytopenia (HIT). These antibodies were shown to be capable of heparin-dependent platelet activation via $\mathrm{Fc} \gamma$ receptor IIa (Fc $\gamma$ RIIa). ${ }^{10,12,14}$ Immunogenic platelet-activating features of protamine or protamineheparin-complexes and the perioperative presence of $\operatorname{PrAB}$ raise the question for a PrAB-mediated pathomechanism leading to perioperative platelet activation. Therefore, we prospectively analyzed the perioperative prevalence of platelet-activating PrAB in patients undergoing cardiac surgery on $\mathrm{CPB}$ and their impact on clinical outcome parameters.

\section{MATERIAL AND METHODS Study Design}

The present study was a prospective single-center observational study. It aimed to describe the prevalence and time course of the occurrence of $\operatorname{PrAB}$ in patients undergoing cardiac surgical procedures with the use of CPB. The study was approved by the ethical committee of the Faculty of Medicine at Justus Liebig University Giessen, Germany. The trial was designed and conducted in accordance to the Declaration of Helsinki.

\section{Patients and Samples}

Patients were eligible for participation if they were aged more than 18 years, were undergoing any cardiac surgical procedure with the use of $\mathrm{CPB}$, and gave informed consent for study participation. Exclusion criteria were thrombocytopenia $(<100 \mathrm{G} / \mathrm{nL})$ at the time of admission, any known chronic thrombocytopenia or thrombopathy, a history of HIT, or an allergic reaction to heparin or protamine. All patients being referred to the study center during the inclusion period were screened on the day before surgery and, if eligible, invited to participate in the trial. The participants were interviewed, and their clinical data were reviewed for a history of arterial hypertension, obesity, myocardial infarction, thromboembolic events (ischemic cerebral infarction, transitory ischemic attacks, thrombosis), cardiac surgery with $\mathrm{CPB}$, nicotine abuse, or atopy and diabetes mellitus with or without insulin treatment. A sample of $10 \mathrm{~mL}$ native blood was obtained from the participants 1 day before operation (T0), 1 hour after weaning from CPB (T1), 24 hours after operation (T2), and 7 days after operation (T3). Clinical follow-up was continued until discharge from the hospital. We prespecified to exclude patients from analysis if followup until postoperative day 7 was not available. Sample tubes were immediately centrifuged, and sera were stored at $-80^{\circ} \mathrm{C}$ until further processing.

\section{Serologic Studies}

All serologic analyses were conducted after completion of the inclusion period. Therefore, PrAB testing results were not known to the clinicians during the patients' treatment period. Laboratory personnel were blinded to the patients' clinical data. All sera were tested for the presence of antibodies reactive to protamine-heparin-complexes. For this purpose, an established heparin-induced platelet activation assay protocol ${ }^{15}$ was modified. In brief, each sample was tested with washed platelets from 4 different donors in the presence of protamine $\left(2 \mu \mathrm{g} \times \mathrm{mL}^{-1}\right)$ and protamine and heparin in low $\left(0.2 \mathrm{IU} \times \mathrm{mL}^{-1}\right)$ or high $\left(100 \mathrm{IU} \times \mathrm{mL}^{-1}\right)$ concentration. Reactions were placed in microtiter wells containing spherical stir bars and stirred at approximately $500 \mathrm{rpm}$. Wells were examined optically at 5 -minute intervals for loss of turbidity. A serum was interpreted as reactive (positive) if a shift from turbidity to transparency (assessed optically) occurred within 30 minutes in at least 2 of 4 platelet suspensions in the presence of protamine or protamine and $0.2 \mathrm{IU} \times \mathrm{mL}^{-1}$ heparin. Specificity of positive reactions was confirmed by repeated testing in the presence of the Fc $\gamma$ RIIa-blocking monoclonal antibody IV.3 $\left(10 \mu \mathrm{g} \times \mathrm{mL}^{-1}\right)$.

To identify patients positive for heparin-dependent HIT antibodies, all sera also were tested for the presence of HIT-antibodies using a heparin-induced platelet activation assay protocol as previously reported. ${ }^{15}$ In brief, each sample was tested with washed platelets from 4 different platelet donors in the absence (buffer alone) or presence of heparin $\left(0.2 \mathrm{U} \times \mathrm{mL}^{-1}\right.$ and 100 $\left.\mathrm{U} \times \mathrm{mL}^{-1}\right)$. Similar to the PrAB testing, a serum was interpreted as reactive if a shift from turbidity to transparency occurred within 30 minutes in at least 2 of 4 platelet suspensions in the presence of $0.2 \mathrm{U} \times \mathrm{mL}^{-1}$, but not 100 
$\mathrm{U} \times \mathrm{mL}^{-1}$, heparin. Each test included a diluted serum from a patient with HIT as a weak positive control and a serum from a healthy donor as a negative control. According to the PrAB testing, specificity of positive reactions was confirmed by repeated testing in the presence of the Fc $\gamma$ RIIa-blocking monoclonal antibody IV.3 $\left(10 \mu \mathrm{g} \times \mathrm{mL}^{-1}\right)$.

\section{Statistics}

In this exploratory study, an inferential statistical analysis was performed using GraphPad Prism version 6 software (GraphPad Software, Inc, La Jolla, Calif) and $\mathrm{R}$ version 3.1.2. ${ }^{16}$ The primary end point of the trial was the perioperative prevalence of $\operatorname{PrAB}$. The prevalence was described with the total of included patients as reference. Patient characteristics were compared using the Fisher exact test or Student $t$ test as appropriate. Group comparison for postoperative outcome parameters was performed by the Fisher exact test or Student $t$ test between individuals positive for $\operatorname{PrAB}$ and individuals negative for PrAB and HIT antibodies to eliminate possible confounding by HIT antibodies. Risks were calculated as odds ratios (ORs). Residuals of models were tested for normal distribution by maximum-likelihood estimation or D'Agostino-Pearson omnibus normality test. Platelet counts (response variable) over time were analyzed using a linear mixed model with fully crossed fixed effects "time" (categoric, T0-T4) and "PrAB" (categoric, positive/negative) and "patient" as random factor. The analysis was performed using $\mathrm{R}^{16}$ and the packages lme $4,{ }^{17}$ lmerTest, ${ }^{18}$ and lsmeans. ${ }^{19}$

\section{RESULTS}

\section{Patients' Characteristics}

A total of 200 consecutive patients admitted to undergo cardiac surgery with CPB were included between June
2012 and February 2013. A total of 15 patients had to be excluded because they were lost to follow-up as the result of early discharge to another hospital and samples $\mathrm{T} 1$ to T3 were not available. The excluded patients' baseline characteristics did not differ significantly from those of the included patients (Table E1). Thus, samples of 185 patients were analyzed. Patients who were positive for PrAB preoperatively were significantly older than PrAB-negative patients. Otherwise, demographics and cardiovascular risk factors did not differ significantly between patients negative and positive for $\operatorname{Pr} \mathrm{AB}$ at baseline. Frequency of operation types was not significantly different between the groups except for a significantly higher rate of isolated coronary artery bypass grafting in PrAB-negative patients ( $60 \%$ vs $37 \% ; P=.046$ ). Operation time, extracorporeal circulation time, and cardioplegic arrest time did not differ between the groups (Table 1).

\section{Perioperative Prevalence of Protamine-Heparin- Complex Antibodies}

Of the 185 patients analyzed, $24(13.0 \%)$ were positive for PrAB at T0. One hour (T1) and 24 hours (T2) after weaning from $\mathrm{CPB}, \mathrm{PrAB}$ were detected in $13.6 \%$ of patients $(21 /$ $155)$ and $14.2 \%$ of patients (22/155), respectively. Seven days (T3) postoperatively, reactivity was present in $11.9 \%$ of patients (22/185). Altogether, 42 patients showed

TABLE 1. Baseline characteristics

\begin{tabular}{|c|c|c|c|c|}
\hline \multirow[b]{2}{*}{ Parameter } & \multirow[b]{2}{*}{$\begin{array}{c}\text { All patients } \\
\mathbf{n}=185(100 \%)\end{array}$} & \multicolumn{3}{|c|}{ PrAB status at baseline (T0) } \\
\hline & & $\begin{array}{c}\operatorname{PrAB}- \\
\mathrm{n}=161(87.03 \%) \\
\end{array}$ & $\begin{array}{c}\operatorname{PrAB}+ \\
\mathrm{n}=\mathbf{2 4}(12.97 \%) \\
\end{array}$ & $P$ value \\
\hline Age (y; mean, SD) & $69 \pm 10$ & $68 \pm 10$ & $73 \pm 10$ & .037 \\
\hline Female sex $(n ; \%)$ & $53(28)$ & $47(29)$ & $6(25)$ & .81 \\
\hline Body mass index $\left(\mathrm{kg} / \mathrm{m}^{2} ;\right.$ mean, SD) & $27 \pm 4.5$ & $28 \pm 4.6$ & $27 \pm 4.0$ & .52 \\
\hline Arterial hypertension $(\mathrm{n} ; \%)$ & $175(94)$ & $152(94)$ & $23(95)$ & 1.00 \\
\hline Previous myocardial infarction $(\mathrm{n} ; \%)$ & $48(25)$ & $41(25)$ & $7(29)$ & .80 \\
\hline Previous thromboembolic event $(\mathrm{n} ; \%)$ & $28(15)$ & $22(13)$ & $6(25)$ & .21 \\
\hline Repeat surgery on CPB (n; \%) & $12(6.4)$ & $9(5.6)$ & $3(12.5)$ & .19 \\
\hline Nicotine abuse & $88(48)$ & $78(48)$ & $10(42)$ & .66 \\
\hline Active nicotine abuse $(\mathrm{n} ; \%)$ & $26(14)$ & $23(14)$ & $3(13)$ & 1.00 \\
\hline Past nicotine abuse $(\mathrm{n} ; \%)$ & $62(34)$ & $55(34)$ & $7(29)$ & .81 \\
\hline History of atopy & $46(25)$ & $42(26)$ & $4(17)$ & .44 \\
\hline Diabetes mellitus (n; \%) & $61(33)$ & $54(34)$ & $7(29)$ & .81 \\
\hline Without insulin treatment $(\mathrm{n} ; \%)$ & $40(22)$ & $34(21)$ & $6(25)$ & 60 \\
\hline With insulin treatment $(\mathrm{n} ; \%)$ & $21(11)$ & $20(12)$ & $1(4.1)$ & .31 \\
\hline \multicolumn{5}{|l|}{ Type of surgery } \\
\hline Isolated CABG & $106(57)$ & $97(60)$ & $9(37)$ & .041 \\
\hline Valve surgery & $48(26)$ & $40(25)$ & $8(33)$ & .45 \\
\hline Surgery on thoracic aorta & $4(2.2)$ & $2(1.2)$ & $2(8.3)$ & .082 \\
\hline Combination & $25(14)$ & $21(13)$ & $4(17)$ & .74 \\
\hline Other & $2(1.1)$ & $1(0.62)$ & $1(4.2)$ & .24 \\
\hline Operation time (min; 95\% CI) & $221(213-231)$ & $221(212-230)$ & $224(193-255)$ & .83 \\
\hline $\mathrm{CPB}$ time $(\mathrm{min} ; 95 \% \mathrm{CI})$ & $102(96-109)$ & $101(95-108)$ & $108(84-133)$ & .45 \\
\hline Cardioplegic arrest time $(\min ; 95 \% \mathrm{CI})$ & $68(63-72)$ & $67(62-72)$ & $74(54-93)$ & .33 \\
\hline
\end{tabular}

Demographics and intraoperative data of the 185 patients included in the study and their status regarding reactivity to protamine or PrAB before cardiac surgery on $\mathrm{CPB}$. Boldface indicates statistical significance. $\operatorname{Pr} A B$, Protamine-heparin-complex antibody; $T 0,1$ day before operation; $S D$, standard deviation; $C B P$, cardiopulmonary bypass; $C A B G$, coronary artery bypass grafting; $C I$, confidence interval. 
reactivity at any time point. Sera of 10 patients were strongly reactive at all time points.

\section{Predictors for Preoperative Presence of Protamine- Heparin-Complex Antibodies}

Different preoperative characteristics were evaluated. "Repeat surgery with CPB," "previous myocardial infarction," "previous thromboembolic event," "diabetes mellitus without insulin treatment," and "arterial hypertension" showed a positive association with preoperative presence of $\operatorname{PrAB}$, but this did not reach statistical significance. "Age $>70$ years" was significantly associated with the preoperative presence of PrAB (OR, 4.14; 95\% confidence interval [CI], 1.47-11.64). Of note, diabetes mellitus with insulin treatment was not associated with the preoperative presence of $\operatorname{PrAB}$ (OR, 0.46; 95\% CI, 0.057-3.76). All other analyzed parameters were not associated with preoperative reactivity (Table 2).

\section{Patients Positive for Protamine-Heparin-Complex Antibodies at Baseline Receive Higher Doses of Protamine}

Heparin doses administered before the induction of CPB were primarily estimated according to internal standard protocol (300 IU/kg body weight). The activated clotting time (ACT) was measured in 30-minute intervals, and additional heparin boluses were given to maintain an ACT greater than 480 seconds during $\mathrm{CPB}$. The initial protamine dose was calculated according to the amount of heparin administered (1 mg protamine to neutralize $100 \mathrm{IU}$ heparin) and infused over 5 minutes after weaning from $\mathrm{CPB}$. A control of the ACT was performed after 10 minutes, and additional protamine was given if necessary to achieve an ACT less than 130 seconds. The mean heparin dose did

TABLE 2. Associations of preoperative variables with preoperative formation of protamine-heparin-complex antibodies

\begin{tabular}{lcc}
\hline \multicolumn{1}{c}{ Parameter } & $\begin{array}{c}\text { OR }(\text { PrAB }+ \text { vs } \\
\text { PrAB }- \text { at T0) }\end{array}$ & $\begin{array}{c}\boldsymbol{P} \\
\text { value }\end{array}$ \\
\hline Age $>70 \mathrm{y}$ & $4.14(1.47-11.64)$ &. $\mathbf{0 0 4 3}$ \\
Female gender & $0.80(0.30-2.16)$ & .81 \\
BMI $>26 \mathrm{~kg} / \mathrm{m}^{2}$ & $0.68(0.28-1.62)$ & .50 \\
Arterial hypertension & $1.36(0.16-11.26)$ & 1.00 \\
Previous myocardial infarction & $1.21(0.46-3.11)$ & .80 \\
Previous thromboembolic event & $2.11(0.75-5.89)$ & .21 \\
Repeat surgery with CPB & $2.41(0.60-9.63)$ & .19 \\
Active nicotine abuse & $0.85(0.23-3.11)$ & 1.00 \\
Past nicotine abuse & $0.79(0.31-2.03)$ & .82 \\
Diabetes mellitus without insulin treatment & $1.25(0.46-3.38)$ & .61 \\
Diabetes mellitus with insulin treatment & $0.31(0.039-2.39)$ & .32 \\
History of atopy & $0.57(0.18-1.75)$ & .45 \\
\hline Potential risk factors for preoperative formation of PrAB were investigated \\
comparing characteristics of preoperatively PrAB-positive and PrAB-negative \\
patients. The risks for PrAB formation are expressed as ORs with 95\% CI. Boldface \\
indicates statistical significance. $O R$, Odds ratio; PrAB, protamine-heparin-complex \\
antibody; $T 0,1$ day before operation; $B M I$, body mass index; $C P B$, cardiopulmonary \\
bypass. & &
\end{tabular}

not differ between the groups $(41,674$ IU $[95 \% \mathrm{CI}$, $39,167-44,181]$ vs 38,888 IU [95\% CI, 38,021-39,755], respectively, $P=.1195$ ). However, patients who were $\operatorname{PrAB}$ positive at baseline required additional protamine nonsignificantly more often (15/24 [62.5\%] vs 77/161 $[47.83 \%] ; P=.19)$. The additional protamine administration resulted in a significantly higher mean total intraoperative dose of protamine in PrAB-positive patients compared with PrAB-negative patients after weaning from CPB (47.66 mg [95\% CI, 44.44-50.88] vs $42.37 \mathrm{mg}$ [95\% CI, 41.42-43.32]; $P=.027$ ) (Figure 1). In addition, 3 of $24(13 \%)$ PrAB-positive patients and 8 of 165 (4.9) PrAB-negative patients (OR, 2.804; 95\% CI, 0.68-11.41; $P=.15$ ) received additional protamine (mean dose: 50 $\mathrm{mg}$ in PrAB-positive patients; $61 \mathrm{mg}$ in PrAB-negative patients; $P=.40$ ) until 24 hours postoperatively on the intensive care unit because of heparin rebound.

\section{Clinical Short-Term Outcome}

To avoid distortion of outcome results by confounding HIT antibodies and to assess the isolated clinical impact of PrAB, patients were divided into 4 groups: group 1, patients negative for PrAB and HIT-antibodies; group 2, patients positive for PrAB; group 3, patients positive for HIT-antibodies; and group 4, patients who could not be assigned to groups 1 to 3 because of unknown antibody status at any time point. No patient was positive for HIT antibodies at baseline. A total of 19 of 185 patients $(10.27 \%)$ were positive for HIT antibodies postoperatively. None of the patients were positive for both PrAB and HIT antibodies at any time point. Because PrAB-mediated platelet activation might initiate a pathomechanism similar to HIT, the perioperative platelet count, quantified at $\mathrm{T} 0, \mathrm{~T} 1, \mathrm{~T} 2$, and
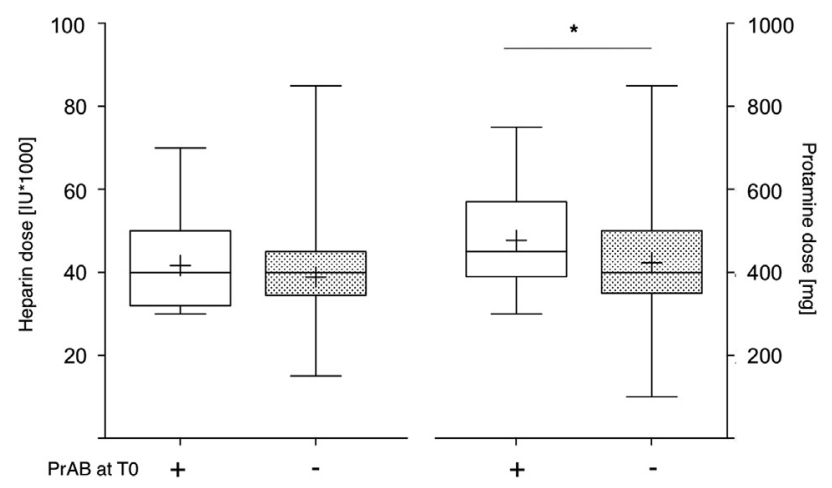

FIGURE 1. Heparin and protamine doses administered to patients undergoing CPB. Left: Heparin doses (IU) administered before induction of CPB were similar in patients negative and positive for PrAB at baseline. Right: Protamine doses $(\mathrm{mg})$ administered after weaning from CPB. Patients positive for $\operatorname{Pr} A B$ at baseline received significantly more protamine after weaning from $\mathrm{CPB}$ than patients negative for $\operatorname{Pr} \mathrm{AB}$ at baseline. Box: interquartile range; whisker: minimum to maximum; + : mean. Data were normally distributed. $\operatorname{Pr} A B$, Protamine-heparin-complex antibody; $T 0,1$ day before operation. $* P=.027$. 
T3, in group 2 compared with group 1 was of particular interest. Group 2 showed slightly higher platelet numbers compared with group 1 preoperatively (258 G/nL [95\% CI, 223-293] vs $243 \mathrm{~g} / \mathrm{nL}$, [95\% CI, 231-255]; $P=.29$ ). The analysis showed an expected decrease of platelet numbers immediately after CPB to $64 \%$ of the preoperative value in group 1 and $63 \%$ in group 2 due to hemodilution, bleeding, and mechanical platelet consumption. The platelet numbers 7 days postoperatively were $256 \mathrm{~g} / \mathrm{nL}$ (95\% CI, 222-289) in group 2 and $289 \mathrm{~g} / \mathrm{nL}(95 \% \mathrm{CI}$, 272-306) in group 1 (Figure 2).

To determine whether the postoperative platelet numbers differed between the groups, a linear mixed model was applied. The analysis of the residuals indicated an analysis using the log-transformed response. By using the logtransformed response, the 4 smallest values occurred as obvious outliers (all values were $<50 \mathrm{~g} / \mathrm{hL}$, the smallest being $2.46 \mathrm{~g} / \mathrm{nL}$ ). Removal of the outliers made the model reach a marginal significance of the interaction at the 5\% level. However, the precision was too low to identify a particular time point at which the presence of the antibody had an expected nonzero effect on the response values with sufficient confidence. Using all data including the 4 outliers led to a similar overall results except that the interaction was nonsignificant. Dunnett contrasts to T0 show a decrease of cell counts in T1 and T2 $(P<.001)$. The difference to T3 was significant in the absence of antibody $(P<.001)$ but not in its presence.

In regard to possible bleeding complications or thromboembolic complications resulting from platelet activation, patients positive for $\operatorname{Pr} \mathrm{AB}$ at any time point had no higher

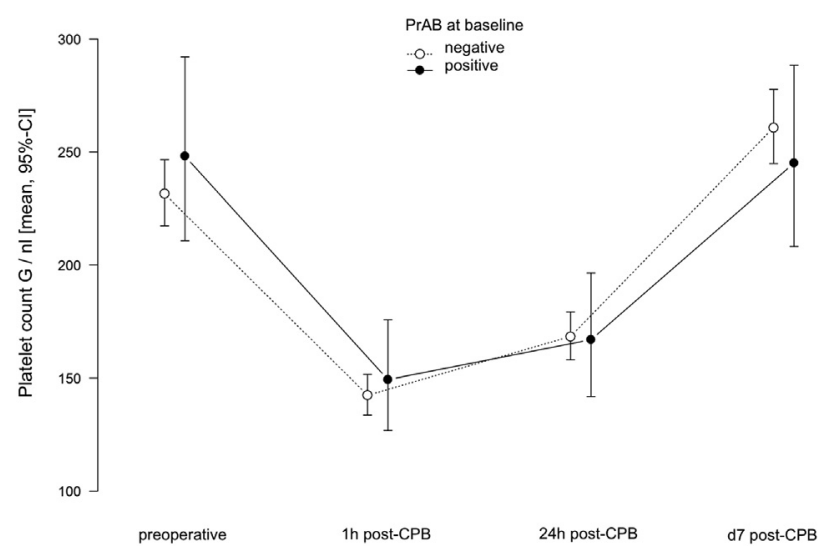

FIGURE 2. Perioperative platelet count of PrAB-negative and PrABpositive patients Platelet count was compared between PrAB-negative $(\mathrm{n}=161)$ and PrAB-positive patients $(\mathrm{n}=24)$ preoperatively. Platelet numbers declined in the immediate perioperative period in both groups in a similar fashion. Subsequently, the platelet counts in both groups showed a recovery toward preoperative values. Outliers were included in the calculation of this graph. $\operatorname{Pr} A B$, Protamine-heparin-complex antibody; $C I$, confidence interval; $C P B$, cardiopulmonary bypass. probability to receive red blood cells $(\mathrm{OR}, 0.82 ; 95 \% \mathrm{CI}$, $0.38-1.78 ; P=.69$ ) or platelet transfusions (OR, 1.09; $95 \%$ CI, $0.45-2.64 ; P=.82$ ) perioperatively. The total drainage volumes from mediastinal and pleural drains were comparable in both groups (group 1: $1050 \mathrm{~mL}$ [95\% CI, 874-1226]; group 2: $984 \mathrm{~mL}$ [95\% CI, 803-1166]; $P=.66)$. The prevalence of reexploration because of excessive bleeding was lower in group 2 compared with group 1 , without statistical significance $(1 / 39 ; 2.6 \%$ vs $7 / 97 ; 7.2 \%$; $P=.45)$. The prevalence of thromboembolic events was comparable in group 2 and group $1(1 / 39 ; 2.6 \%$ and $4 / 97$; $4.1 \% ; P=1.00)$. A combined major cardiovascular and cerebrovascular events (MACCE) end point (circulatory arrest, death, cerebrovascular event, myocardial infarction) occurred less frequently in PrAB-positive patients (2/39; $5.1 \%$ ) compared with PrAB-negative patients (9/97; 9.3\%; OR, 0.51; 95\% CI, 0.11-2.48; $P=.50$ ). Thromboembolic events and MACCE were not observed in patients positive for HIT antibodies (Table 3).

To evaluate the postoperative inflammatory response, C-reactive protein and white blood cell count were measured (data not shown), showing no significant differences between the groups. Also, patients with preoperative PrAB had similar levels of C-reactive protein and leucocytes at all time points. The analysis of perioperative renal function showed a tendency toward renal impairment in patients with $\operatorname{PrAB}$ reactivity at all time points compared with the other groups. However, the creatinine and urea values remained stable postoperatively independently of $\operatorname{PrAB}$ status. None of the PrAB-negative and PrABpositive patients developed new terminal renal insufficiency with chronic need for hemodialysis postoperatively.

\section{DISCUSSION}

In the present prospective study, we demonstrate that the preoperative presence of platelet-activating $\operatorname{PrAB}$ leads to an increased protamine demand for heparin neutralization after CPB. The presence of these antibodies was associated with a slower postoperative recovery of the platelet count, resulting in a lower platelet number 7 days postoperatively. Other short-term outcomes were not affected by the presence of PrAB.

In total, $13 \%$ of patients tested positive preoperatively. This is in accordance with previous observations. ${ }^{10}$ The presence of PrAB before surgery has been correlated with peripheral vascular disease, previous myocardial infarction, and diabetes mellitus. ${ }^{12}$ These data were based on a cohort of 7 seropositive individuals only. Because neutral protamine Hagedorn (NPH) was a commonly used adjunct in long-acting insulin, patients with insulin treatment are likely to have been exposed to protamine. Several studies have shown the formation of PrAB in individuals treated with such insulins. ${ }^{20,21}$ Our data failed to show a correlation between diabetes mellitus and the presence of 
TABLE 3. Impact of protamine-heparin-complex antibodies on postoperative outcome after cardiopulmonary bypass

\begin{tabular}{|c|c|c|c|c|c|c|c|}
\hline Outcome parameter & $\begin{array}{c}\text { All patients } \\
\mathbf{n}=\mathbf{1 8 5}(\mathbf{1 0 0} \%)\end{array}$ & $\begin{array}{c}\text { Group 1: } \\
\text { PrAB - and } \\
\text { HIT-AB - at } \\
\text { all time points } \\
\mathbf{n}=97(53 \%)\end{array}$ & $\begin{array}{c}\text { Group 2: } \\
\text { PrAB + and } \\
\text { HIT-AB - at } \\
\text { any time point } \\
\text { n=39 }(21 \%)\end{array}$ & $\begin{array}{c}\text { Group 3: } \\
\text { HIT-AB + } \\
\text { and PrAB - at } \\
\text { any time point } \\
\mathrm{n}=19(10 \%)\end{array}$ & $\begin{array}{c}\text { Group 4: } \\
\text { Unknown antibody } \\
\text { status at any } \\
\text { time point } \\
\mathbf{n}=\mathbf{3 0}(\mathbf{1 6} \%)\end{array}$ & $\begin{array}{c}\text { OR (group } 2 \text { vs } \\
\text { group 1; 95\% CI) }\end{array}$ & $\begin{array}{c}P \\
\text { value }\end{array}$ \\
\hline $\begin{array}{l}\text { Erythrocyte transfusion } \\
\text { required }(\mathrm{n} ; \%)\end{array}$ & $122(65)$ & $64(66)$ & $24(61)$ & $12(63)$ & $22(73)$ & $0.82(0.38-1.78)$ & .69 \\
\hline $\begin{array}{l}\text { Platelet transfusion } \\
\text { required }(\mathrm{n} ; \%)\end{array}$ & $39(21)$ & $21(22)$ & $9(23)$ & $4(21)$ & $5(17)$ & $1.09(0.45-2.64)$ & .82 \\
\hline $\begin{array}{l}\text { Total drainage volume } \\
\text { from pleural and } \\
\text { mediastinal drains } \\
(\mathrm{mL} ; \text { mean, } 95 \% \mathrm{CI})\end{array}$ & $1048(937-1159)$ & $1050(874-1226)$ & $984(803-1166)$ & 1178 (917-1439) & & $\begin{array}{l}\text { Difference: } \\
\quad-233 \text { to }+365\end{array}$ & .66 \\
\hline $\begin{array}{l}\text { Reexploration due to } \\
\text { bleeding (n; \%) }\end{array}$ & $11(5.9)$ & $7(7.2)$ & $1(2.6)$ & $1(5.3)$ & $2(0.67)$ & $0.34(0.04-2.85)$ & .45 \\
\hline $\begin{array}{l}\text { Thromboembolic events } \\
\qquad(\mathrm{n} ; \%)\end{array}$ & $5(2.7)$ & $4(4.1)$ & $1(2.6)$ & 0 & 0 & $0.61(0.06-5.66)$ & 1.00 \\
\hline MACCE (n; \%) & 14 (7.6) & $9(9.3)$ & $2(5.1)$ & 0 & $3(10)$ & $0.51(0.11-2.48)$ & .50 \\
\hline
\end{tabular}

Evaluation of PrAB status through day 7 postoperatively was correlated with data obtained from clinical follow-up until hospital discharge. HIT antibody status was also determined to eliminate possible confounding of outcomes by HIT antibodies. A total of 39 patients tested positively for PrAB and negative for HIT antibodies at any time point. None of the patients tested positively for both PrAB and HIT antibodies. The antibody status at T1 and T2 was unknown in 30 patients (group 4 ). The analysis shows no impact of PrAB on clinical short-term outcome parameters. Results are expressed as ORs with 95\% CI. PrAB, Protamine-heparin-complex antibody; HIT-AB, heparin-induced thrombocytopenia antibody; $O R$, odds ratio; $C I$, confidence interval; $M A C C E$, major cardiovascular and cerebrovascular events.

platelet-activating protamine-heparin antibodies. On the one hand, this might be explained by the fact that we did only look for platelet-activating heparin-protamine antibodies, because nonfunctional antibodies were not correlated with clinical effects in a previous study ${ }^{10}$; by this approach, we may well have missed protamine antibodies related to the use of insulin. On the other hand, in newer insulins currently being used, modification of insulin molecules is more frequently used to generate long-acting insulin than the addition of NPH. In fact, in our cohort, the majority (20/21) of patients treated with insulin administered new long-acting insulins (not containing NPH), and only 1 patient was taking NPH insulin. Exposure to protamine during previous surgical procedures on $\mathrm{CPB}$ was associated with a higher incidence of $\operatorname{Pr} A B$ formation but did not reach statistical significance.

Possible binding of PrAB to circulating protamine 22 might affect the protamine molecule in its ability to neutralize heparin. We observed that PrAB-positive patients received significantly more protamine after weaning from $\mathrm{CBP}$ than did PrAB-negative patients. Increased use of protamine in PrAB-positive patients might be attributed to a reduced protamine effect after PrAB binding to protamine. The impact of the resulting antigen-antibody complexes is not clear. In parallel to the pathomechanism of HIT, platelet activation and generation of prothrombotic state might follow the formation of such complexes. Thromboembolic events occurred in $2.7 \%$ of cases (5/185) within 7 days after surgery, including 4 strokes and 1 bypass occlusion with no difference of incidences between PrAB-positive (1/39;
$2.6 \%)$ and PrAB-negative patients $(4 / 97 ; 4.1 \%)$. A combined MACCE end point consisting of death, circulatory arrest, cerebrovascular events, and myocardial infarction occurred in $5.1 \%$ of PrAB-positive patients and in 9.3\% of PrAB-negative patients, with no statistical difference. Accordingly, we were unable to support our finding from a previous post hoc analysis, ${ }^{10}$ but this might be an effect of the low number of individuals included in the present study. Other possible effects related to the presence of PrAB including bleeding complications as a consequence of a reduced protamine effect or increased postoperative inflammatory responses as a consequence of antigen/antibody complexes were also not observed.

The analysis of perioperative platelet counts showed no clear interaction of time and preoperative presence of PrAB because the time courses of the platelet counts were not distinctively different depending on the presence of PrAB.

During the first hour postoperatively, the thrombocyte counts decreased from $240 \mathrm{~g} / \mathrm{nL}$ to $150 \mathrm{~g} / \mathrm{hL}$ and stayed on this level at least until 24 hours after operation. After 7 days, the thrombocyte counts recovered to the preoperative values.

\section{CONCLUSIONS}

The results can further substantiate the finding that platelet-activating antibodies against protamine-heparin complexes have biological consequences in patients on CBP receiving protamine. These consequences appear to include a reduced efficacy of protamine and a possibly 
increased platelet clearance with delayed platelet recovery, probably due to platelet activation in vivo. The small number of patients included in this study is a limitation disabling a final conclusion on the clinical effects of PrAB, especially with regard to thromboembolic events. Because reduced protamine response and possibly delayed platelet recovery can be promptly detected in the clinical routine and adequate treatment can be provided instantly, we currently do not propose a standard preoperative screening for the presence of PrAB. However, patients who present with delayed platelet recovery or thromboembolic complications after CBP should be investigated for the presence of such antibodies.

\section{Conflict of Interest Statement}

Philippe Grieshaber reports consulting fees from Maquet and lecture fees for Orion Pharma. Andreas Böning reports consulting fees from Berlin Heart and lecture fees from Maquet, Orion Pharma, and Astra Zeneca. All other authors have nothing to disclose with regard to commercial support.

The authors thank Cornelia Kisselbach for clinical assistance; Astrid Giptner, Lida Röder, and Renate Marschall for technical support; and Dr Ines Florath for assistance with statistics.

\section{References}

1. Kanippayoor RL, Alpern JH, Moehring AJ. Protamines and spermatogenesis in Drosophila and Homo sapiens. Spermatogenesis. 2013;3:e24376. Available at: http://www.ncbi.nlm.nih.gov/pmc/articles/PMC3710222/. Accessed April 27, 2013.

2. Yavari M, Becker RC. Anticoagulant therapy during cardiopulmonary bypass. J Thromb Thrombolysis. 2008;26:218-28.

3. Heise T, Eckers U, Kanc K, Nielsen JN, Nosek L. The pharmacokinetic and pharmacodynamic properties of different formulations of biphasic insulin aspart: a randomized, glucose clamp, crossover study. Diabetes Technol Ther. 2008;10: 479-85.

4. Michaels IA, Barash PG. Hemodynamic changes during protamine administration. Anesth Analg. 1983;62:831-5.

5. Weiss ME, Adkinson NF Jr. Allergy to protamine. Clin Rev Allergy. 1991;9: 339-55.

6. Weiler JM, Gellhaus MA, Carter JG, Meng RL, Benson PM, Hottel RA, et al. A prospective study of the risk of an immediate adverse reaction to protamine sulfate during cardiopulmonary bypass surgery. J Allergy Clin Immunol. 1990 85:713-9.

7. Al-Mondhiry H, Pierce WS, Basarab RM. Protamine-induced thrombocytopenia and leukopenia. Thromb Haemost. 1985;53:60-4.

8. Cuker A, Cines DB. Protamine-induced thrombocytopenia? Blood. 2013;121: 2818-9.

9. Chudasama SL, Espinasse B, Hwang F, Qi R, Joglekar M, Afonina G, et al Heparin modifies the immunogenicity of positively charged proteins. Blood. 2010;116:6046-53.

10. Bakchoul T, Zöllner H, Amiral J, Panzer S, Selleng S, Kohlmann T, et al Anti-protamine-heparin antibodies: incidence, clinical relevance, and pathogenesis. Blood. 2013;121:2821-7.

11. Samuel T, Kolk AH, Rümke P. Studies on the immunogenicity of protamines in humans and experimental animals by means of a micro-complement fixation test Clin Exp Immunol. 1978;33:252-60.

12. Lee GM, Welsby IJ, Phillips-Bute B, Ortel TL, Arepally GM. High incidence of antibodies to protamine and protamine/heparin complexes in patients undergoing cardiopulmonary bypass. Blood. 2013;121:2828-35.

13. Pouplard C, Leroux D, Rollin J, Amiral J, May MA, Gruel Y. Incidence of antibodies to protamine sulfate/heparin complexes in cardiac surgery patients and impact on platelet activation and clinical outcome. Thromb Haemost. 2013;109:1141-7.

14. Singla A, Sullivan MJ, Lee G, Bartholomew J, Kapadia S, Aster RH, et al. Protamine-induced immune thrombocytopenia. Transfusion (Paris). 2013;53: 2158-63.

15. Greinacher A, Michels I, Kiefel V, Mueller-Eckhardt C. A rapid and sensitive test for diagnosing heparin-associated thrombocytopenia. Thromb Haemost. 1991; 66:734-6.

16. R Core Team. R: A language and environment for statistical computing. $\mathrm{R}$ Foundation for Statistical Computing, Vienna, Austria. Available at: http:// www.R-project.org. Accessed March 3, 2015.

17. Bates D, Maechler M, Bolker B, Walker S, Christensen RHB, Singmann H, et al lme4: Linear mixed-effects models using Eigen and S4. Available at: http://cran. r-project.org/web/packages/lme4/index.html. Accessed March 3, 2015.

18. Kuznetsova A, Brockhoff PB, Christensen RHB. lmerTest: Tests in linear mixed effects models. Available at: http://cran.r-project.org/web/packages/lmer Test/index.html. Accessed March 3, 2015.

19. Lenth RV, Hervé M. lsmeans: least-squares means. Available at: http://cran.rproject.org/web/packages/lsmeans/index.html. Accessed March 3, 2015.

20. Kurtz AB, Gray RS, Markanday S, Nabarro JD. Circulating IgG antibody to protamine in patients treated with protamine-insulins. Diabetologia. 1983;25 322-4.

21. Ellerhorst JA, Comstock JP, Nell LJ. Protamine antibody production in diabetic subjects treated with NPH insulin. Am J Med Sci. 1990;299:298-301.

22. Subramaniam P, Skillington P, Tatoulis J. Heparin-rebound in the early postoperative phase following cardiopulmonary bypass. Aust N Z J Surg. 1995; 65:331-3.

Key Words: cardiopulmonary bypass, drug-dependent antibodies, platelet activation, protamine, thrombocytopenia 
TABLE E1. Baseline characteristics of the patients included in the study and the excluded patients

\begin{tabular}{|c|c|c|c|}
\hline Parameter & $\begin{array}{c}\text { Included } \\
\text { patients } \\
n=185\end{array}$ & $\begin{array}{c}\text { Excluded } \\
\text { patients } \\
\mathbf{n}=15\end{array}$ & $P$ value \\
\hline Age (y; mean, SD) & $69 \pm 10$ & $71 \pm 9$ & .44 \\
\hline Female sex $(\mathrm{n} ; \%)$ & $53(28)$ & $2(13)$ & .25 \\
\hline $\begin{array}{l}\text { Body mass index } \\
\qquad\left(\mathrm{kg} / \mathrm{m}^{2} ; \text { mean, } \mathrm{SD}\right)\end{array}$ & $27 \pm 4.5$ & $29 \pm 5.2$ & .43 \\
\hline $\begin{array}{l}\text { Arterial hypertension } \\
\quad(\mathrm{n} ; \%)\end{array}$ & $175(94)$ & $12(80)$ & .062 \\
\hline $\begin{array}{l}\text { Previous myocardial } \\
\text { infarction }(\mathrm{n} ; \%)\end{array}$ & $48(25)$ & $4(27)$ & 1.00 \\
\hline $\begin{array}{l}\text { Previous thromboembolic } \\
\text { event }(\mathrm{n} ; \%)\end{array}$ & $28(15)$ & $2(13)$ & .099 \\
\hline $\begin{array}{l}\text { Repeat surgery on } \mathrm{CPB} \\
\quad(\mathrm{n} ; \%)\end{array}$ & $12(6.4)$ & 0 & .92 \\
\hline Nicotine abuse & $88(48)$ & $8(53)$ & .79 \\
\hline $\begin{array}{l}\text { Active nicotine abuse } \\
\quad(\mathrm{n} ; \%)\end{array}$ & $26(14)$ & $4(27)$ & .25 \\
\hline $\begin{array}{l}\text { Past nicotine abuse } \\
\quad(\mathrm{n} ; \%)\end{array}$ & $62(34)$ & $4(27)$ & .31 \\
\hline History of atopy & $46(25)$ & $6(40)$ & .22 \\
\hline Diabetes mellitus (n; \%) & $61(33)$ & $6(40)$ & .58 \\
\hline $\begin{array}{l}\text { Without insulin } \\
\text { treatment }(\mathrm{n} ; \%)\end{array}$ & $40(22)$ & $3(20)$ & 1.00 \\
\hline $\begin{array}{l}\text { With insulin treatment } \\
(\mathrm{n} ; \%)\end{array}$ & $21(11)$ & $3(20)$ & .40 \\
\hline \multicolumn{4}{|l|}{ Type of surgery } \\
\hline Isolated CABG & $106(57)$ & $11(73)$ & .28 \\
\hline Valve surgery & $48(26)$ & $2(13)$ & .37 \\
\hline $\begin{array}{l}\text { Surgery on thoracic } \\
\text { aorta }\end{array}$ & $4(2.2)$ & $1(6.7)$ & .33 \\
\hline Combination & $25(14)$ & $2(13)$ & 1.00 \\
\hline Other & $2(1.1)$ & 0 & 1.00 \\
\hline $\begin{array}{l}\text { Operation time } \\
\qquad(\min ; 95 \% \mathrm{CI})\end{array}$ & $221(213-231)$ & $225(191-259)$ & .85 \\
\hline CPB time (min; $95 \% \mathrm{CI})$ & $102(96-109)$ & $106(86-126)$ & .78 \\
\hline $\begin{array}{l}\text { Cardioplegic arrest time } \\
\quad(\min ; 95 \% \mathrm{CI})\end{array}$ & $68(63-72)$ & $82(48-116)$ & .17 \\
\hline
\end{tabular}

nary bypass; $C A B G$, coronary artery bypass grafting; $C I$, confidence interval. 